\title{
Ultrasound-Assisted Method for the Synthesis of Tertiary Fatty Aliphatic Esters with Potential Antimicrobial Activity
}

\author{
Dragomir Vassilev 1,*(D), Nadezhda Petkova ${ }^{2}$ (D) , Milena Koleva ${ }^{1}$, Panteley Denev 2 (D) \\ 1 Technical University of Gabrovo, Dep. "Physics, Chemistry and Ecology", 4, Hadji Dimitar str., Gabrovo 5300, \\ Bulgaria \\ 2 University of Food Technologies, Dep. of Inorganic and Organic chemistry, 26 Maritza blvd., Plovdiv, Bulgaria \\ * Correspondence: dvasilevl@tugab.bg;
}

Received: 26.04.2020; Revised: 21.05.2020; Accepted: 23.05.2020; Published: 27.05.2020

\begin{abstract}
This study aims to demonstrate a simple and rapid "green" method for the ultrasound-assisted synthesis of t-aliphatic esters by reacting $\mathrm{t}$-butanol with saturated (capric, lauric, palmitic) and unsaturated (oleic and undecylenic) acids. The spectral characterization of esters was performed by IR and NMR spectroscopies. The impact of ultrasonic irradiation on the reaction in comparison with the conventional method was analyzed based on the reaction time and the yield of the resulting esters. After spectroscopic studies, the synthesis of the corresponding esters after the ultrasound-assisted irradiation was proven. The yields of the $t$-butyl fatty acid esters increased between 2 and $10 \%$ in comparison with the conventional method for their synthesis. It was also established that the application of ultrasonic irradiation intensifies the esterification process significantly compared to the conventional method. The advantages of the ultrasound-assisted esterification include shortening the reaction time; the process is carried out at room temperature instead of at the conventional reaction temperature $67-70^{\circ} \mathrm{C}$. The application of ultrasonic-assisted irradiation for esterification is a suitable and promising method to reduce energy consumption, shortening the reaction time, and increasing the yield of $\mathrm{t}$-butyl fatty acid esters.
\end{abstract}

Keywords: t-aliphatic esters, "green" method, ultrasound-assisted.

(C) 2020 by the authors. This article is an open-access article distributed under the terms and conditions of the Creative Commons Attribution (CC BY) license (https://creativecommons.org/licenses/by/4.0/).

\section{Introduction}

Fischer esterification is a process that requires boiling a reflux condenser of the mixture of alcohol and fatty acid in a strong acid (often $10 \% \mathrm{H}_{2} \mathrm{SO}_{4}$ ) [1, 2]. In many reactions, the heating continues for hours, and the temperature can be reached within several hours. High temperatures and prolonged heating can lead to the formation of by-products and breakdown of unsaturated fatty acids. To avoid these deficiencies, in recent years, esterification has been aided by the application of ultrasonic effects.

W. Steglich offers a simple method [3] for the synthesis of tert-butyl esters and DMAP catalyst (4-N, N-dimethylaminopyridine). The preparation of tertiary esters is hampered by the spatial interference of the methyl groups. In addition, with prolonged heating and the presence of strong acid as a catalyst, the yield of ester decreases significantly because tert- $\mathrm{BuOH}$ tends to lose water and becomes isobutene.

Palmitate ester of L-ascorbic acid was synthesized by esterification in the presence of conc. $\mathrm{H}_{2} \mathrm{SO}_{4}$ as solvent and catalyst by US at $25 \mathrm{kHz}$ [4]. 
Primary alcohol esters are synthesized by transesterification of sucrose with aliphatic esters and ultrasound. It is noteworthy that the reaction is selective, and only the monoester is obtained [5]. Described is the development of a new synthetic method using ultrasonic irradiation and sodium methoxide as a catalyst for a series of pyridinic sucrose esters (py-SEs), derived from transesterification of sucrose with picolinic, nicotinic and isonicotinic methyl esters [6].

The effect of ultrasonic energy is also used in the synthesis of carbohydrate esters, such as sucrose and raffinose esters. Octa- $O$-acetylsucrose was synthesized by the esterification of sucrose with acetic anhydride using US energy [7]. Raffinose fatty acid monoesters were synthesized by acylation of raffinose with aliphatic methyl esters under ultrasound energy [8].

Undecylenic acid and their esters have a variety of biologically active properties. Perlman, back in 1949, suggests the use of undecylenic acid as a therapeutic agent for psoriasis, neurodermatitis, and related arthropathies. However, undecylenic acid and its salts are used as topical agents for the treatment of various fungal skin infections. Undecylenic acid is an oilsoluble, unsaturated fatty acid, which is usually obtained by the thermal conversion of castor oil derived from castor oil. In nature, traces of undecylenic acid are found in human tears and hair.

Undecylenic acid products have been used by Yong and co-authors in the preparation of preparations that improve the intratumoral distribution of anticancer agents, with significantly improved stability under physiological conditions. Its methyl and ethyl esters are used in the perfumery, zinc salts have an antimitotic effect, and sucrose esters - antimicrobial [9-11].

The industrial application of biodiesel has prompted in-depth study and the application in the production of methyl and ethyl esters of higher fatty acids by transesterification of triglycerides. [12] These reactions are made easy only with primary alcohols. Similar conditions have been used by Hanh et al. [13] for the synthesis of sucrose esters.

Synthesis of biodiesel from a non-edible source as Pistacia khinjuk seed oil via ultrasonic cavitation (UC) system was reported by Saira Asif [14].

Possibilities for the application of ionic liquids in sonochemistry have been studied [15, $16]$.

The synthesis of esters of secondary alcohols by transesterification of palm oil and isopropyl alcohol by sonochemistry requires a long time (6 hours) in acidic media. Esters of primary alcohols can be obtained by direct esterification with ultrasonic irradiation. For example, Hobuss et al. [1] and Pacheco, B et al. [17], synthesized esters by treating mixtures of methanol and ethanol with caprylic, capric, lauric, myristic and palmitic acids with ultrasound (20 kHz) for 15-30 min. obtaining amounts of esters comparable and, in some cases, higher than those obtained by conventional esterification for 120 minutes.

Ultrasound has been found to influence the rate of chemical reactions in solution through the cavitation process and the generation of microbubbles. This process is characterized by the formation, growth, and implosive disintegration of gas bubbles in the solution. Inside cavitation bubbles, it has been found that pressure and temperature reach high values - according to Mason and Peters [18] in cavitation bubbles, the temperature can reach up to $1000 \mathrm{~K}$ and hundreds of atmospheres of pressure. At the same time, the temperature of the acoustic medium as a whole rises from 20 to $30-35^{\circ} \mathrm{C}$, as opposed to the high temperature in conventional synthesis. Obviously, a lower temperature will determine a higher value of the 
equilibrium constant of esterification, leading to an increase in the amount of the end product - the ester.

The method we suggest features a short process time and low temperature, which allows the synthesis of undecylenic esters of secondary and tertiary alcohols in high yield, without side colored and isomeric products, while preserving the location of the double bond, which is the carrier of biological activity.

The use of principles of "green" chemistry like ultrasound and microwave energy in modern technologies is widespread - in organic synthesis and modification of organic compounds, for the degradation of environmental pollutants, in medicine, etc. [19-24]

The research into the use of the ultrasonic power in the synthesis of esters is promising in organic synthesis. Its effect on the esterification process in the preparation of aliphatic esters of short-chain and medium-chain fatty acids has not yet been sufficiently studied. [25-27]

The purpose of this study is to obtain tertiary aliphatic esters by reacting t-butanol with capric, lauric, palmitic, undecylenic, and oleic acids. The yield of the esters obtained was studied by comparing the conventional method and the ultrasonic method.

\section{Materials and Methods}

\subsection{Reagents and apparatus.}

All reagents used are an analytical grade. An ultrasonic bath (Dimoff A-2/2, Bulgaria) with $100 \mathrm{~W}$ generator power and $44 \mathrm{kHz}$ operating frequency was used for the synthesis. A circulation thermostat was used to maintain the temperature regimes of the synthesis. The IR spectra of the esters were recorded on a Nicolet Avatar IR (FT Thermo Scientific, USA) in a $\mathrm{KBr}$ tablet in the range of 4000 to $500 \mathrm{~cm}^{-1}$. The ${ }^{1} \mathrm{H}$ and ${ }^{13} \mathrm{C}$ NMR spectra were recorded on a Bruker $500 \mathrm{MHz}$ spectrometer using a solvent $\mathrm{CD}_{3} \mathrm{Cl}$ and an internal TMS standard.

\subsection{Conventional synthesis.}

$t$-butanol $(0.5 \mathrm{~mol})$ was placed in a $300 \mathrm{ml}$ Erlenmeyer flask, 2 mmol conc. $\mathrm{H}_{2} \mathrm{SO}_{4}$ added as a catalyst, followed by the addition of $4 \mathrm{mmol}$ of the corresponding fatty acid (capric, lauric, palmitic, oleic, and 10-undecylenic acid).

The flask was connected to a reflux condenser with water cooling and heat at boiling. After $120 \mathrm{~min}$, the reaction mixture was cooled to room temperature and poured into $100 \mathrm{ml}$ of distilled water. A three-fold extraction with $50 \mathrm{ml}$ of hexane was performed. The combined hexane layer was washed with $10 \% \mathrm{Na}_{2} \mathrm{CO}_{3}$ and dried with anhydrous $\mathrm{Na}_{2} \mathrm{SO}_{4}$. Then the hexane was distilled. The ester obtained was separated, and the yield was determined by weight.

\subsection{Ultrasound-assisted synthesis.}

t-butanol $(0.5 \mathrm{~mol})$ was placed in a $300 \mathrm{ml}$ Erlenmeyer flask, 2 mmol conc. $\mathrm{H}_{2} \mathrm{SO}_{4}$ added as a catalyst, followed by the addition of $4 \mathrm{mmol}$ of the corresponding fatty acid (capric, lauric, palmitic, oleic, and 10-undecylenic acid).

The flask was connected to a reflux condenser with water cooling, and it was placed in an ultrasonic bath. The irradiation continues for $15 \mathrm{~min}$ at room temperature. After completion of the reaction, the alcohol was distilled in a vacuum, and 20-30 ml of distilled water was added to the residue. The extraction was carried out three times, with $50 \mathrm{ml}$ of hexane each. 
The combined hexane extracts were washed with $10 \% \mathrm{Na}_{2} \mathrm{CO}_{3}$ and dried with anhydrous $\mathrm{Na}_{2} \mathrm{SO}_{4}$, after which the hexane was distilled. The ester obtained was separated, and the yield was determined by weight.

$t$-butyl caprate - $15 \mathrm{mg}$ in $0.6 \mathrm{ml} \mathrm{CHCl} 3,{ }^{1} \mathrm{H} \mathrm{NMR}\left(500 \mathrm{MHz}, \mathrm{CDCl}_{3}\right) \delta 2.36-2.33(\mathrm{t}$, $2 \mathrm{H}), 1.66-1.60(\mathrm{~m}, 2 \mathrm{H}), 1.37-1.21(\mathrm{~m}, 21 \mathrm{H}), 0.89-0.87(\mathrm{t}, 3 \mathrm{H}) .{ }^{13} \mathrm{C}$ NMR $(126 \mathrm{MHz}$, $\left.\mathrm{CDCl}_{3}\right) \delta 173.47,79.93,35.65,34.05,31.86,29.71,29.45,29.39,29.31,29.27,29.24,29.10$, 29.06, 29.04, 28.12, 25.13, 24.68, 22.66, 14.10 .

$t$-butyl laurate - $10 \mathrm{mg}$ in $0.6 \mathrm{ml} \mathrm{CHCl}_{3},{ }^{1} \mathrm{H} \mathrm{NMR}\left(500 \mathrm{MHz}, \mathrm{CDCl}_{3}\right) \delta 2.36-2.33(\mathrm{t}$. $2 \mathrm{H}), 1.66-1.60(\mathrm{~m}, 2 \mathrm{H}), 1.44-1.26(25 \mathrm{H}), 0.89-0.87$ (t. $3 \mathrm{H}) .{ }^{13} \mathrm{C} \mathrm{NMR}\left(126 \mathrm{MHz}, \mathrm{CDCl}_{3}\right) \delta$ 179.56, 33.96, 31.91, 29.59, 29.43, 29.33, 29.24, 29.06, 28.12, 24.69, 22.69, 14.11.

$t$-butyl palmitate - $20 \mathrm{mg}$ and $0.6 \mathrm{ml}$ of $\mathrm{CHCl}_{3},{ }^{1} \mathrm{H} \mathrm{NMR}\left(500 \mathrm{MHz}, \mathrm{CDCl}_{3}\right) \delta 2.36$ $2.33(\mathrm{t}, 2 \mathrm{H}), 1.66-1.60(\mathrm{~m}, 2 \mathrm{H}), 1.44-1.26(\mathrm{~m}, 33 \mathrm{H}), 0.89-87(\mathrm{t}, 3 \mathrm{H}) .{ }^{13} \mathrm{C} \mathrm{NMR}(126 \mathrm{MHz}$, $\left.\mathrm{CDCl}_{3}\right) \delta 172.56,77.22,31.93,29.69,29.67,29.64,29.59,29.44,29.37,29.24,29.07,24.69$, $22.70,14.12$.

$t$-butyl-10-undecylenate - $10 \mathrm{mg}$ in $0.6 \mathrm{ml} \mathrm{CHCl}_{3},{ }^{1} \mathrm{H} \mathrm{NMR}\left(500 \mathrm{MHz}, \mathrm{CDCl}_{3}\right) \delta 5.85$ $5.77(\mathrm{ddt}, 1 \mathrm{H}), 5.01-4.91(\mathrm{~m}, 2 \mathrm{H}), 2.30-2.27(\mathrm{t}, 2 \mathrm{H}), 2.05-2.01(\mathrm{~m}, 2 \mathrm{H}), 1.63-1.58(\mathrm{~m}$, $4 \mathrm{H}), 1.42-1.29(\mathrm{~m}, 14 \mathrm{H}), 0.95-0.92(\mathrm{~m}, 3 \mathrm{H}) .{ }^{13} \mathrm{C} \mathrm{NMR}\left(126 \mathrm{MHz}, \mathrm{CDCl}_{3}\right) \delta 174.03,139.18$, 114.13, 64.11, 34.40, 33.78, 30.71, 29.29, 29.20, 29.13, 29.05, 28.89, 25.01, 19.15, 13.71.

$t$-Butyl oleate - $10 \mathrm{mg}$ in $0.6 \mathrm{~mL} \mathrm{CHCl}_{3},{ }^{1} \mathrm{H} \mathrm{NMR}\left(500 \mathrm{MHz}, \mathrm{CDCl}_{3}\right) \delta 5.34(\mathrm{dt}, 2 \mathrm{H})$, $2.34(\mathrm{t}, 2 \mathrm{H}), 2.01(\mathrm{dd}, 4 \mathrm{H}), 1.62(\mathrm{~d}, J=7.3 \mathrm{~Hz}, 2 \mathrm{H}), 1.32$ (dd, $J=57.3,35.5 \mathrm{~Hz}, 29 \mathrm{H}), 0.87$ (d, $J=7.0 \mathrm{~Hz}, 3 \mathrm{H})$.

\section{Results and Discussion}

Saturated and unsaturated fatty acid t-Bu esters were synthesized: t-butyl caprate, $\mathrm{t}$ butyl laurate, t-butyl palmitate, t-butyl-10-undecylenate and t-butyl oleate. The obtained t-butyl oleate and t-butyl undecylenate are colorless liquids, while the rest are white solid waxy substances. The yields of the obtained esters in conventional and ultrasonic are presented in Table 1.

Table 1. Effect of conditions (type) of synthesis, reaction time, and yield of esters obtained.

\begin{tabular}{l|c|c}
\hline \multirow{2}{*}{ Ester } & \multicolumn{2}{|c}{ Yield,\% } \\
\cline { 2 - 3 } & Conventional synthesis & Ultrasound synthesis \\
\hline t-Butyl caprate & $80 \pm 0,2$ & $85 \pm 0,2$ \\
\hline t-Butyl laurinate & $75 \pm 0,2$ & $85 \pm 0,2$ \\
\hline t-Butyl palmitate & $80 \pm 0,2$ & $87 \pm 0,2$ \\
\hline t-Butyl undecylenate & $75 \pm 0,2$ & $79 \pm 0,2$ \\
\hline t-Butyl oleate & $78 \pm 0,2$ & $80 \pm 0,2$ \\
\hline
\end{tabular}

The results presented in Table 1 showed that the synthesized esters were produced in high yield, the synthesis is carried out by ultrasonic action, and the reaction time was also significantly reduced from 120 minutes to 15 minutes.

The spectra highlight several areas typical of esters. Fig. 1 shows the IR spectra of the synthesized esters by ultrasound. The characteristic band at $1743 \mathrm{~cm}^{-1}$ due to the valence vibrations $(\mathrm{vC}=\mathrm{O})$ of the ester was clearly visible in the spectra of the synthesized esters.

An increase in the intensity of symmetric and asymmetric valence vibrations was observed at 2857-2945 $\mathrm{cm}^{-1}$ typical of the methylene groups of the alkyl chain.

The IR spectra of $\mathrm{t}-\mathrm{Bu}$ undecylenate and t-Bu oleate contained the typical features of the synthesized ester bands described so far - a decrease in the intensity of $3300 \mathrm{~cm}^{-1}$ with the 
appearance of a peak at about $1743 \mathrm{~cm}^{-1}$ which is typical of $v(\mathrm{C}=\mathrm{O})$, but others appear, too. The detection of strips at 3000-3075 $\mathrm{cm}^{-1} v(=\mathrm{C}-\mathrm{H})$ and $1641 \mathrm{~cm}^{-1} v(\mathrm{C}=\mathrm{C})$ was evidence of a double bond at the terminal olefin, which confirmed the attachment of the undecylenic chain (C11:1 (10)), as well as maintaining its stability during synthesis.

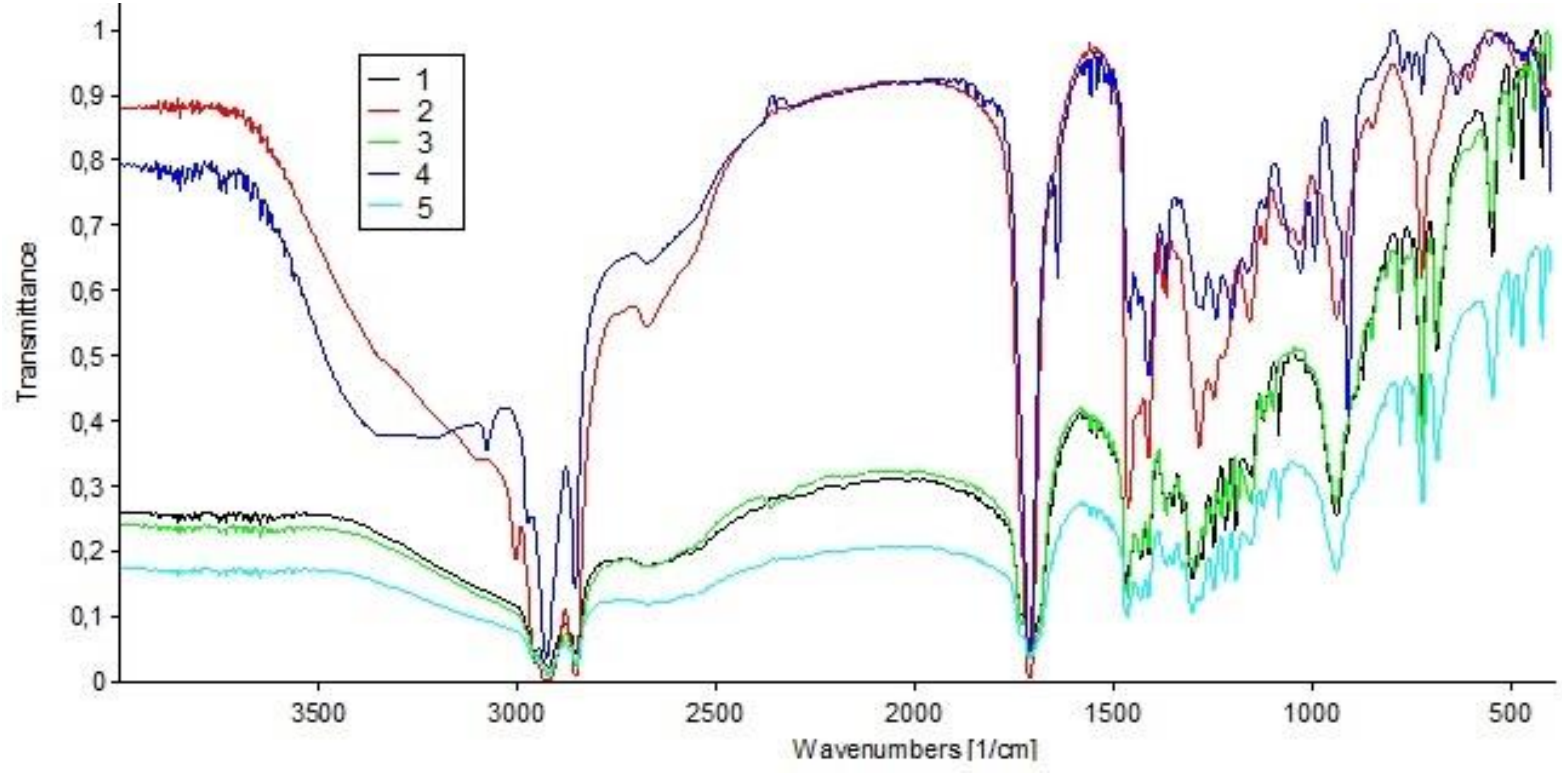

Figure 1. FT-IR spectrum of synthesized t-butyl esters of higher fatty acids - capric (1), lauric (5), palmitic (3), 10-undecylenic (4), and oleic (2).

In ${ }^{1} \mathrm{H}$ NMR spectra of the synthesized esters, typical bands were observed. The methyl groups of the aliphatic chain were appeared at $0.99 \mathrm{ppm}$ and those of the t-butyl residue - at $1.49 \mathrm{ppm}$. The methylene groups were clearly outlined as triplets and multiplets in the range of 1.30 to $2.36 \mathrm{ppm}$. The presence of a band for the methylene group to an ester at $2.36 \mathrm{ppm}$ was proof of the successful synthesis. Bands at 4.99 and $5.65 \mathrm{ppm}$ (figure 2) at t-butyl undecylenate proved the presence of $\mathrm{CH}=\mathrm{CH}_{2}$ protons, while a signal for $\mathrm{CH}=\mathrm{CH}$ protons at $5.47 \mathrm{ppm}$ was observed in the spectrum of t-butyl oleate. (Figure 3).

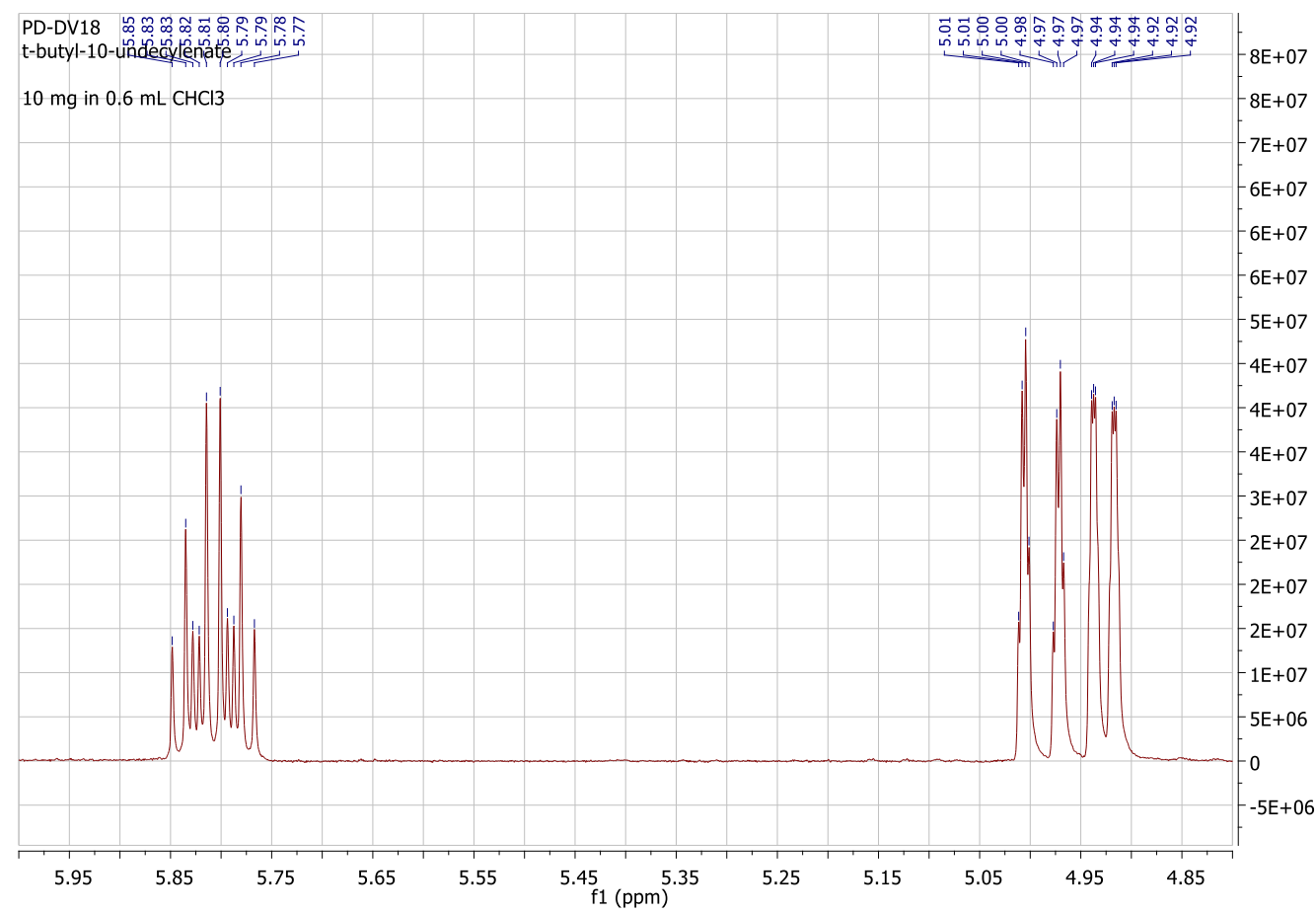

Figure 2. ${ }^{1} \mathrm{H}$ NMR spectrum $\left(500 \mathrm{MHz}, \mathrm{CD}_{3} \mathrm{Cl}\right)$ of t-butyl undecylenate in the range 4.8-6 ppm. 
Saturated and unsaturated fatty acid t-Bu esters were synthesized: t-butyl caprate, $\mathrm{t}$ butyl laurate, t-butyl palmitate, t-butyl-10-undecylenate and t-butyl oleate. The obtained t-butyl oleate and t-butyl undecylenate are colorless liquids, while the rest are white solid waxy substances. The yields of the obtained esters in conventional and ultrasonic are presented in Table 1.

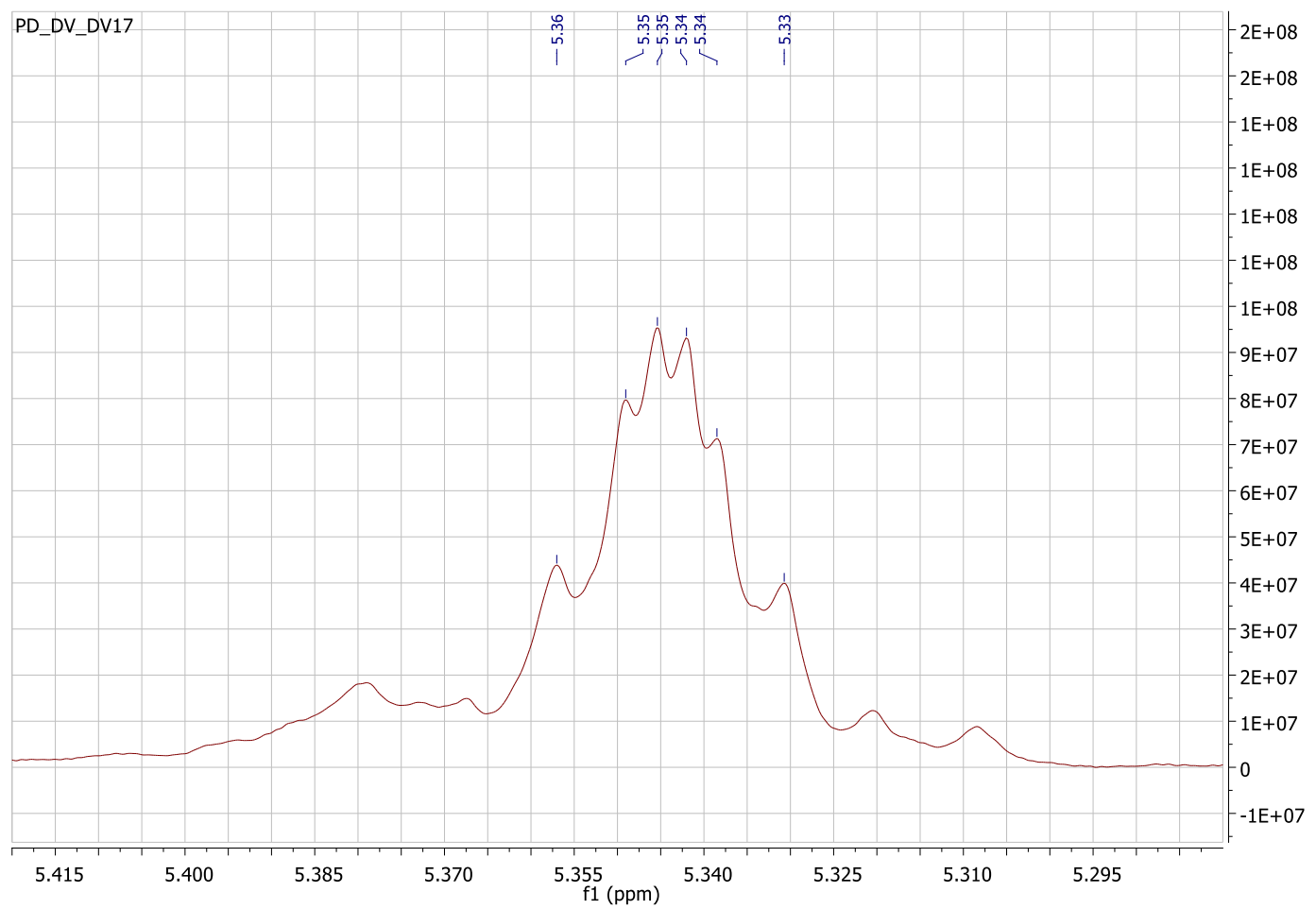

Figure 3. ${ }^{1} \mathrm{H}$ NMR spectrum $\left(500 \mathrm{MHz}, \mathrm{CD}_{3} \mathrm{Cl}\right)$ of t-butyl oleate in the range 5.28-5.42 ppm.

The signals of a carbonyl carbon atom at $172.83 \mathrm{ppm}$, for a tertiary carbon atom at $81.62 \mathrm{ppm}$, and for methyl groups at $28.3 \mathrm{ppm}$ (at a tertiary $\mathrm{C}$ atom), and $14.02 \mathrm{ppm}$ (from the aliphatic acid chain) were observed in the collected spectral data on ${ }^{13} \mathrm{C}$ NMR. Unsaturated t-

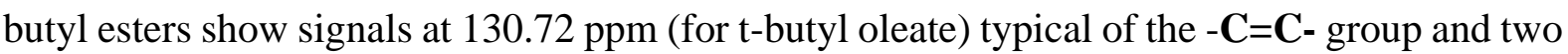
signals in the t-butyl undecylenate spectrum at $115.35 \mathrm{ppm}(=\mathbf{C H}-)$ and $139.0 \mathrm{ppm}\left(\mathrm{CH}_{2}=\right)$.

In our previous research study [28] has been conducted for the antimicrobial activity of 10-undecylenic esters. Antimicrobial properties of the 10-undecylenic esters revealed that most of the esters had insignificant antibacterial activity. A promising antifungal potential is demonstrated by t-butyl-10-undecylenate.

In this regard, the remaining t-butyl esters also have the potential for future antifungal agents, part of which activity is a research process.

\section{Conclusions}

As a result of the application of ultrasound, the corresponding esters were obtained in the process of esterification of t-butanol with fatty acids (saturated and unsaturated). A significant reduction in the reaction time was achieved compared to the conventional method (from 2 hours to $15 \mathrm{~min}$ ); at the same time, the process was carried out at room temperature rather than at $67-70^{\circ} \mathrm{C}$, resulting in a reduction in energy consumption. The yield of the obtained products was increased by between 2 and $10 \%$ compared to the conventional method. 
The use of ultrasonic technology in esterification was an appropriate and promising method to decrease energy consumption, reduce reaction time, and increase the yield of the products obtained.

The obtained esters can be successfully used as potential antifungal agents for various pharmaceutical products, food packaging, and plant protection products.

\section{Funding}

This research was financially supported by Fund Science Contract No 1805C, Technical University of Gabrovo, Gabrovo, Bulgaria.

\section{Acknowledgments}

This research has no acknowledgment.

\section{Conflicts of Interest}

The authors declare no conflict of interest.

\section{References}

1. Hobuss, C.B.; Venzke, D.; Pacheco, B.S.; Souza, A.O.; Santos, M.A.Z.; Moura, S.; Quina, F.H.; Fiametti, K.G.; Vladimir Oliveira, J.; Pereira, C.M.P. Ultrasound-assisted synthesis of aliphatic acid esters at room temperature. Ultrasonics Sonochemistry 2012, 19, 387-389, https://doi.org/10.1016/j.ultsonch.2011.06.020.

2. Boffito, D.C.; Galli, F.; Pirola, C.; Bianchi, C.L.; Patience, G.S. Ultrasonic free fatty acids esterification in tobacco and canola oil. Ultrasonics Sonochemistry 2014, 21, 1969-1975, https://doi.org/10.1016/j.ultsonch.2014.01.026.

3. Neises, B.; Steglich, W. Simple Method for the Esterification of Carboxylic Acids. Angewandte Chemie International Edition in English 1978, 17, 522-524, https://doi.org/10.1002/anie.197805221.

4. Wen, B.; Eli, W.; Xue, Q.; Dong, X.; Liu, W. Ultrasound accelerated esterification of palmitic acid with vitamin C. Ultrasonics Sonochemistry 2007, 14, 213-218, https://doi.org/10.1016/j.ultsonch.2006.02.003.

5. Hanh, H.D.; Dong, N.T.; Okitsu, K.; Nishimura, R.; Maeda, Y. Biodiesel production by esterification of oleic acid with short-chain alcohols under ultrasonic irradiation condition. Renewable Energy 2009, 34, 780783, https://doi.org/10.1016/j.renene.2008.04.001.

6. Mora Vargas, J.A.; Ortega, J.O.; dos Santos, M.B.C.; Metzker, G.; Gomes, E.; Boscolo, M. A new synthetic methodology for pyridinic sucrose esters and their antibacterial effects against Gram-positive and Gramnegative strains. Carbohydrate Research 2020, 489, https://doi.org/10.1016/j.carres.2020.107957.

7. Petkova, N.; Vassilev, D.; Arabadzhieva, R.; Tumbarski, Y.; Vasileva, I.; Koleva, M.; Denev, P. "Green" Synthesis of Sucrose Octaacetate and Characterization of Its Physicochemical Properties and Antimicrobial Activity *. Chemical and Biochemical Engineering Quarterly 2017, 31, 395-402, https://doi.org/10.15255/CABEQ.2017.1117.

8. Lu, Y.; Yan, R.; Ma, X.; Wang, Y. Synthesis and characterization of raffinose fatty acid monoesters under ultrasonic irradiation. European Food Research and Technology 2013, 237, 237-244, https://doi.org/10.1007/s00217-013-1985-y.

9. Newell, G.W.; Petretti, A.K.; Reiner, L. Studies in Acute and Chronic Toxicity of Undecylenic Acid. Journal of Investigative Dermatology 1949, 13, https://doi.org/10.1038/jid.1949.81.

10. www.activemicrotechnologies.com, Antimicrobial Product List - 2018

11. Yong, T.; Hu, J.; Zhang, X.; Li, F.; Yang, H.; Gan, L.; Yang, X. Domino-Like Intercellular Delivery of Undecylenic Acid-Conjugated Porous Silicon Nanoparticles for Deep Tumor Penetration. ACS Applied Materials \& Interfaces 2016, 8, 27611-27621, https://doi.org/10.1021/acsami.6b11127.

12. Mohammed, S., H. Abbas, H. Alshihi, F. Mabood, E. Yousif, A. Ali, Z. Hussain, K. Riami, Assessment of Nanocalcite Synthesis Routs on Green Biodiesel Production: Comparative Study, Biointerface Research in Applied Chemistry 2020, 10, 6139 - 6147, https://doi.org/10.33263/BRIAC105.61396147.

13. Huang, D.; Jiang, X.; Zhu, H.; Fu, X.; Zhong, K.; Gao, W. Improved synthesis of sucrose fatty acid monoesters under ultrasonic irradiation. Ultrasonics Sonochemistry 2010, 17, 352-355, https://doi.org/10.1016/j.ultsonch.2009.08.009.

14. Asif, S.; Ahmad, M.; Bokhari, A.; Chuah, L.F.; Klemeš, J.J.; Akbar, M.M.; Sultana, S.; Yusup, S. Methyl ester synthesis of Pistacia khinjuk seed oil by ultrasonic-assisted cavitation system. Industrial Crops and Products 2017, 108, 336-347, https://doi.org/10.1016/j.indcrop.2017.06.046. 
15. Masri, A.N.; Abdul Mutalib, M.I.; Yahya, W.Z.N.; Aminuddin, N.F.; Leveque, J.M. Rapid esterification of fatty acid using dicationic acidic ionic liquid catalyst via ultrasonic-assisted method. Ultrasonics Sonochemistry 2020, 60, https://doi.org/10.1016/j.ultsonch.2019.104732.

16. Yan, J.; Zhao, Y.; Li, K.; Zhang, H.; Fan, L.; Lu, Z. Efficient production of biodiesel from ionic liquid catalyzed esterification using ultrasonic-microwave combined intensification. Chemical Engineering and Processing - Process Intensification 2020, 149, https://doi.org/10.1016/j.cep.2020.107870.

17. Pacheco, B.S.; Nunes, C.F.P.; Rockembach, C.T.; Bertelli, P.; Mesko, M.F.; Roesch-Ely, M.; Moura, S.; Pereira, C.M.P. Eco-friendly synthesis of esters under ultrasound with p-toluenesulfonic acid as catalyst. Green Chemistry Letters and Reviews 2014, 7, 265-270, https://doi.org/10.1080/17518253.2014.941950.

18. Mason, T.; Peters, D. Practical sonochemistry. Horwood Publishing Limited, 2011

19. Kritchenkov, A.S.; Egorov, A.R.; Volkova, O.V.; Kritchenkov, I.S.; Kurliuk, A.V.; Shakola, T.V.; Khrustalev, V.N. Ultrasound-assisted catalyst-free phenol-yne reaction for the synthesis of new watersoluble chitosan derivatives and their nanoparticles with enhanced antibacterial properties. International Journal of Biological Macromolecules 2019, 139, 103-113, https://doi.org/10.1016/j.ijbiomac.2019.07.203.

20. Zhang, Y.; Dai, Y.; Hou, H.; Li, X.; Dong, H.; Wang, W.; Zhang, H. Ultrasound-assisted preparation of octenyl succinic anhydride modified starch and its influence mechanism on the quality. Food Chemistry: $X$ 2020, 5, https://doi.org/10.1016/j.fochx.2020.100077.

21. Cercado, A.P.; Ballesteros, F.; Capareda, S. Ultrasound assisted transesterification of microalgae using synthesized novel catalyst. Sustainable Environment Research 2018, 28, 234-239, https://doi.org/10.1016/j.serj.2018.03.002.

22. Carmona-Cabello, M.; Sáez-Bastante, J.; Pinzi, S.; Dorado, M.P. Optimization of solid food waste oil biodiesel by ultrasound-assisted transesterification. Fuel 2019, 255, 1 https://doi.org/10.1016/j.fuel.2019.115817.

23. Vassilev, D.; Petkova, N.; Koleva, M.; Denev, P. Microwave Synthesis of Inulin Acetate as Potential BioBased Additive for Poly(Vinyl Chloride). Journal of Renewable Materials 2018, 6, 707-714, https://doi.org/10.32604/JRM.2018.00015.

24. Petkova, N.; Gencheva, G.; Vassilev, D.; Koleva, M.; Krastanov, A.; Denev, P. Microwave-Assisted Isolation and Acetylation of Inulin from Helianthus Tuberosus L Tubers. 2018, 6, 671-679, https://doi.org/10.32604/JRM.2018.00001.

25. Fadda, A.; Mohammed, A.; Abdel-Galil, E. Synthesis and antimicrobial evaluation of some 4-quinolinylazoN-pyrimidinyl benzenesulfonamide derivatives, Biointerface Research in Applied Chemistry 2020, 10, 48464852, https://doi.org/10.33263/BRIAC101.846852.

26. Murugan, N.; Natarajan, D. Bionanomedicine for antimicrobial therapy - a case study from Glycosmis pentaphylla plant mediated silver nanoparticles for control of multidrug resistant bacteria, Letters in Applied NanoBioScience, 2018, 8, 523 - 540, https://doi.org/10.33263/LIANBS834.523540.

27. El-Gammal, O.; Fouda, A.; Nabih, D. Synthesis, spectral characterization, DFT and in vitro antibacterial activity of $\mathrm{Zn}(\mathrm{II}), \mathrm{Cd}(\mathrm{II})$ and $\mathrm{Hg}(\mathrm{II})$ complexes derived from a new thiosemicarbazide, Letters in Applied NanoBioScience, 2019, 8, 715 - 722, https://doi.org/10.33263/LIANBS84.715722.

28. Vassilev, D.; Petkova, N.; Tumbarski, Y.; Koleva, M.; Denev, P. Application of the Principles of "Green Chemistry" for the Synthesis of 10-Undecylenic Aliphatic Esters with Antimicrobial Activity. Journal of Renewable Materials 2020, 8 (5), https://doi.org/10.32604/jrm.2020.09279. 